\title{
El prácticum en la formación de maestros: percepciones de los protagonistas
}

Practicum in Teacher Development Education: Participants' Perceptions Le practicum dans la formation des enseignants: perceptions des protagonistes

O prácticum na formação de professores: percepções dos protagonistas

Fecha de recepción: 29 DE MAYO DE 2015/Fecha de aceptación: 25 DE ENERO DE 2017/Fecha de disponibilidad en línea: 16 DE MAYO DE 2017 Encuentre este artículo en http://magisinvestigacioneducacion.javeriana.edu.co/

Escrito por José TeJadA-FERnÁNDEZ Universidad Autónoma de Barcelona, UAB Barcelona, España jose.tejada@uab.cat

Maria LuRdes Carvalho-Dias UnIVERSIDAD DEL MiÑo lurdesdc@ie.uminho.pt

Carmen Ruiz-Bueno Universidad Autónoma de Barcelona, UAB Barcelona, España carmen.ruiz.bueno@uab.cat

\section{Resumen}

El objetivo del artículo es analizar las percepciones sobre el Prácticum en los procesos de adquisición de competencias y de construcción de la identidad profesional en la formación inicial de maestros de educación infantil y primaria de la Universidad Autónoma de Barcelona, UAB.

Se presentan los resultados de un estudio de caso, obtenidos por medio de entrevistas a tutores, trianguladas con un cuestionario a los estudiantes. Se concluye sobre el frágil trabajo colaborativo y la débil coordinación entre tutores, la poca observación y orientación in situ del ejercicio profesional, y se valora la reflexión individual y colectiva, mediada por el tutor universitario.

\section{Palabras clave}

Práctica pedagógica; tutoría; competencia profesional; identidad profesional; formación profesional superior

\section{Transferencia a la práctica}

El artículo ilustra el papel del prácticum en el proceso de adquisición de competencias profesionales y la construcción de la identidad profesional, para evidenciar en la realidad de su gestión y desarrollo la fuerte presencia de argumentos organizacionales frente a los propiamente formativos. En este sentido, los resultados y las conclusiones de la investigación dan pie a la necesidad de ajuste del modelo actual a las nuevas realidades de los tutores, tanto universitarios como de centros, por lo que se refiere al trabajo colaborativo, la coordinación entre las instituciones y el propio seguimiento in situ.

Para citar este artículo / To cite this article / Pour citer cet article / Para citar este artigo

Tejada-Fernández, José; Carvalho-Dias, Maria Lurdes \& Ruiz-Bueno, Carmen (2017). El prácticum en la formación de maestros: percepciones de los protagonistas. magis, Revista Internacional de Investigación en Educación, 9 (19), 91-114. doi: 10.11144/Javeriana.m9-19.pfmp 


\section{Keywords}

Pedagogical practice; tutoring; professional competence; professional identity; higher education

\section{Mots clés}

Pratique pédagogique; tutorat; compétence professionnelle; identité professionnelle; formation professionnelle supérieure

\section{Abstract}

The aim of the article is to analyze the perceptions about the Practicum in the process of acquiring professional competences and in the construction of a professional identity within the initial teacher education program of pre-primary and primary teachers of Universidad Autónoma of Barcelona, UAB.

We present the results of a case study, which were collected through interviews conducted with tutors, and triangulated with a questionnaire answered by students. We conclude that there is a fragile collaborative work and a weak coordination among tutors, as well as little observation and in situ guidance of the professional practice. We value individual and collective reflection, mediated by the university tutor.

\section{Transfer to practice}

The article examines the role of practicum in the process of acquiring professional competences and in the construction of a professional identity, in order to reveal the strong presence of organizational arguments instead of those that are mainly educational. In this sense, results and conclusions of the research help explain the need to adjust the current model to the new realities of tutors, both located at universities and institutions, in terms of collaborative work, coordination between institutions and on-site follow-up.

\section{Palavras-chave}

Prática pedagógica; tutoria; competência profissional; identidade profissional; formação profissional superior

\section{Résumé}

L'objectif de l'article est d'analyser les perceptions par rapport au Practicum dans les processus d'acquisition de compétences et de la construction d'identité professionnelle dans la formation initiale des enseignants d'éducation enfantine et primaire de I'Université Autónoma de Barcelona UAB. On présente les résultats d'une étude de cas, obtenus au moyen d'entretiens aux tuteurs; triangulées avec un questionnaire aux étudiants. On conclut qu'il y a un travail collaboratif fragile et une faible coordination entre tuteurs, le peu d'observation et orientation in situ de l'exercice professionnel, et on considère la réflexion individuelle et collective, qui est facilité par le tuteur universitaire.

\section{Transfert à la pratique}

L"article illustre le rôle du practicum dans le processus d'acquisition de compétences professionnelles et la construction de l'identité professionnelle, pour montrer dans la réalité de sa gestion et développement la forte présence d'arguments organisationnels par rapport aux proprement formatifs. Dans ce sens, les résultats et les conclusions de la recherche évidence le besoin d'ajuster le modèle actuel aux nouvelles réalités des tuteurs, tantôt les universitairs que ceux des instituts, en ce qui concerne le travail collaboratif, la coordination entre les institutions et le propre suivi in situ.

\section{Resumo}

O objetivo do artigo é analisar as percepções sobre o Prácticum nos processos de aquisição de competências e de construção da identidade profissional na formação inicial de professores de educação infantil e primária da Universidade Autônoma de Barcelona, UAB

Apresentam-se os resultados de um estudo de caso, obtidos por meio de entrevistas a tutores, trianguladas com um questionário aos estudantes. Conclui-se sobre o frágil trabalho colaborativo e a débil coordenação entre tutores, a pouca observação e orientação in situ do exercício profissional, e valoriza-se a reflexão individual e coletiva mediada pelo tutor universitário.

\section{Transferência à prática}

O artigo ilustra o papel do prácticum no processo de aquisição de competências profissionais e a construção da identidade profissional, para evidenciar na realidade de seu gerenciamento e desenvolvimento, a forte presença de argumentos organizacionais frente aos propriamente formativos. Neste sentido, os resultados e as conclusões da pesquisa dão pé à necessidade de ajuste do modelo atual às novas realidades dos tutores, tanto universitários como de outros centros, pois se refere ao trabalho colaborativo, à coordenação entre as instituições e ao próprio rastreamento in situ. 


\section{Introducción}

Focalizamos el estudio en el análisis del Prácticum en cuanto espacio privilegiado de articulación entre las propuestas originarias de las diversas áreas curriculares que constituyen la formación inicial más teórica en la universidad y otra, más práctica, ante las exigencias de los contextos en los centros educativos, para reconocer una apropiación gradual de competencias profesionales e identitarias, fundamentada en procesos de investigación-acción-reflexión colaborativa. Este espacio de Prácticum es también un tiempo en que el estudiante tiene oportunidad de experimentar los aprendizajes, conocimientos y relaciones interpersonales, adquiridos en su formación — saber, saber-hacer, saber ser y estar, saber convivir-, imbuidos de hábitos de reflexión, de comprensión de las incertidumbres existentes en el proceso del desempeño profesional o la actividad docente cotidiana.

\section{Marco conceptual}

En el Prácticum, consideramos "la acción y la práctica profesional como referentes y como estrategias formativas" (Tejada-Fernández, 2013, p. 177), caracterizado por el trabajo colaborativo (gráfico 1) entre los actores implicados (profesor tutor-estudiante, maestro tutor-estudiante, estudiante-estudiante) y por su perfil interdisciplinar, arraigado en lógicas metodológicas de articulación curricular y de innovación en y entre la universidad y los centros de Prácticum.

Igualmente, el Prácticum, a la vez, es "la interconexión entre el mundo formativo y el mundo productivo" (Tejada-Fernández, 2006, p. 2), un "espacio formativo" de "circularidad de saberes" (Jean-Louis Martinand, 2004, citado por Lüdke, 2009, p. 102) y un tiempo en que los estudiantes "aprenden haciendo" (Schön, 1992, pp. 45-46), un tiempo de experimentación de propuestas educativas, fundamentadas y planeadas para un contexto real y concreto, solo posible por "coherencia", "centralidad" y "complementariedad" (Zabalza, 2013) pero también reciprocidad existente entre la universidad y las instituciones educativas.

Gráfico 1

El Prácticum como espacio-tiempo de adquisición de conocimiento e identidad profesional

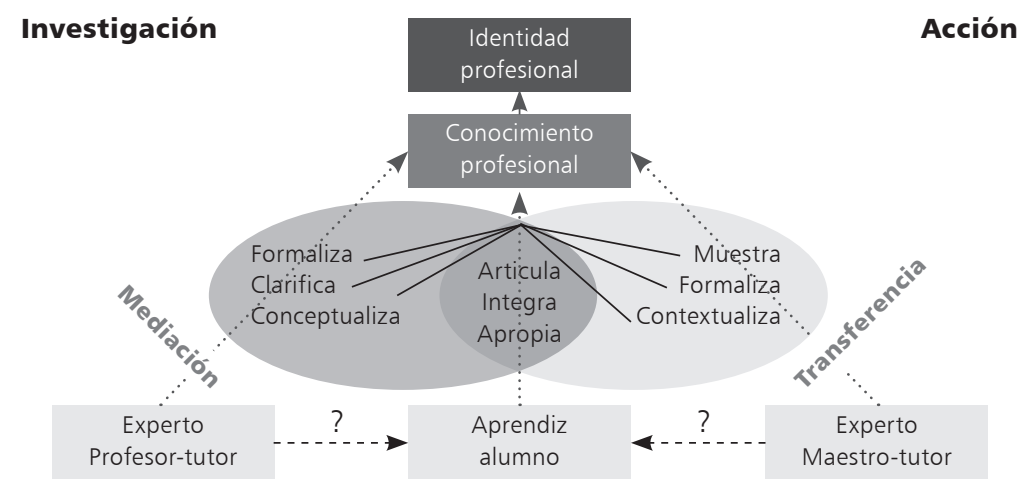

Reflexión

Colaboración
Descripción del artículo | Article description | Description de l'article | Artigo descrição

Este artículo de investigación, derivado del proyecto El prácticum: tiempo y espacio de aprendizaje en la formación inicial de profesionales de la educación, presenta las percepciones de los protagonistas del Prácticum (tutores y estudiantes) sobre el proceso de adquisición de competencias y la construcción de la identidad profesional. Se trata de un estudio de caso descriptivointerpretativo de dos titulaciones de formación inicial docente (grado infantil y grado de primaria) de la $\cup A B$, que triangula las miradas de los protagonistas en una complementariedad metodológica cuantitativa-cualitativa. 
Los saberes profesionales son saberes trabajados, elaborados, modelados, incorporados a las situaciones profesionales y son, en cada momento reconstruidos, adaptados y aplicados de forma significativa y con apropiación a cada situación, y constituyen saberes de acción y "acerca de la acción" (Day, 2005), "saberes del trabajo", "saberes en el trabajo" (Tardif, 2004). A la vez, estos saberes en la acción reflejan las capacidades, lo que permite aumentar la "confianza y motivación" (Judith Scheele, 2009, citada por Rodríguez-Quezada, Cisterna-Cabrera \& Gallegos-Muñoz, 2011, p. 71-72).

El conjunto de los conocimientos adquiridos sobre la práctica surge inicialmente de la "reflexión sobre la práctica" (Lopes-Menino \& Blázquez-Entonado, 2012, p. 27) y de la "reflexión en la acción" que, articulando el conocimiento en la acción (Tejada-Fernández, 2012), se manifiesta al compartir experiencias, a partir del análisis de diferentes argumentos científicos, del análisis crítico de prácticas de otros y de otras posibilidades de acción o reacción, tantas veces capaces de permitir una coconstrucción o significado personal.

Este proceso cíclico, gradualmente más complejo, de saberes del y en el trabajo que lleva a la construcción del proceso de identidad profesional, es consecuencia de una coconstrucción de saberes evolucionados hasta competencias y que ondula en la transferencia de las relaciones, colegialidad, responsabilidad y ética entre los "expertos" y los "aprendices". Todos ellos constituyen los elementos clave del Prácticum que con sus funciones diferenciadas, siguen un camino convergente para el mismo fin (Ruiz-Bueno, Carvalho \& Tejada, 2014).

Este espacio formativo está inicialmente en manos de los maestros tutores que, como profesionales expertos, trabajan colaborativamente en la construcción del conocimiento profesional, por medio de la concepción de propuestas y sus cómo y porqué, de la creación de espacio de reflexión, de cuestionamiento, de observación atenta y perspicaz, de la elaboración de proyectos y planos de actuación, de la demostración de estrategias diversificadas, de la ampliación de recursos, lo cual fomenta la innovación educativa.

Estamos frente a una "comunidad de prácticas" (Wenger, 2002), definida como un grupo de personas con una práctica común, recurrente y estable en el tiempo y, por lo tanto, con intereses y problemas importantes y comunes a los elementos del grupo, que reflexionan y desarrollan el conocimiento de forma colaborativa y compartida, para prestar ayuda adecuada al "aprendiz" en su lugar de trabajo (Aguilera, Mendoza, Racionero \& Soler, 2010). "Todo el equipo (tutores universitarios, maestros tutores y estudiantes) constituyen los elementos clave del Prácticum, que con sus funciones diferenciadas, siguen un camino convergente para el mismo fin, creando 'comunidades profesionales de aprendizaje' que, integrando solo personas de una misma 'familia profesional' buscan el crecimiento profesional y la mejora de calidad" (Carvalho \& Tejada-Fernández, 2013, p. 3).

Esto nos sitúa en un escenario de cambio profundo que afecta la organización de la docencia, las metodologías, el papel de los actores y los mismos modelos formativos, al considerar la alternancia de contextos de formación como una encrucijada y complemento de la teoría con la práctica (CoidurasRodríguez, 2010; Korthagen, 2010; Lentzen, 2015; Palomares-Montero \& Chisvert-Tarazona, 2016; Romeu, Guitert \& Sangrà, 2015; Tejada-Fernández \& Ruiz-Bueno, 2013), cuyo análisis excede los límites de este trabajo.

Creado este espacio y tiempo, los estudiantes tienen oportunidades de sumergirse en la profesionalidad docente, al observar la articulación entre la teoría y la práctica en un contexto real de actividad laboral, para elaborar proyectos de aprendizaje, descubrir y adquirir su identidad profesional, testar sus competencias, en suma, al apropiarse del conocimiento profesional que fueron adquiriendo (Ballesteros-Moscosio \& Ries, 2014; Carvalho \& Tejada-Fernández, 2013; Monereo \& Domínguez, 2014; Tejada-Fernández, 2009). De forma gradual, los estudiantes promueven oportunidades, al adquirir y desarrollar competencias personales y profesionales, movilizar de forma interrelacionada conocimientos, actitudes y procedimientos que dependen, simultáneamente, del empeño personal y de la existencia de un contexto favorable.

\section{Metodología}

La síntesis que presentamos en este artículo es parte de un proyecto de investigación más amplio en el ámbito del Prácticum, en el contexto específico de la formación de profesionales de educación (en este caso, maestros de educación infantil y primaria). El principal objetivo del presente estudio de carácter descriptivo-interpretativo es averiguar las percepciones de los diferentes actores del Prácticum en la formación de los referidos profesionales de la Universitat Autònoma de Barcelona (UAB) sobre el proceso de formación práctica y la construcción de la identidad profesional de los futuros docentes, en el nuevo contexto y los planes de formación, relativos específicamente a la formación de grado, en el proceso de convergencia europea (Proceso de Bolonia)' ${ }^{1}$, en el que el Estado español está comprometido.

\footnotetext{
1 Así se reconoce el proceso de construcción del Espacio Europeo de Educación Superior.
} 
Desde un planteamiento de una metodología mixta - cuantitativa y cualitativa - y desde una perspectiva de triangulación de fuentes, fueron realizadas entrevistas a una muestra de los coordinadores y tutores universitarios de grado de infantil y primaria en un total de 11 informantes (coordinadores de grado de infantil y primaria $(n=2)$, profesores tutores académicos de los distintos Prácticum que constituyen el currículo de formación ( $n=8$ ), vicedecana de Prácticum $(n=1)$ ). En el mismo sentido, se contó con una muestra de 9 maestros - tutores- del centro (5 de infantil y 4 de primaria, siendo, a la vez, 1 coordinador de prácticas y 2 jefe de estudios), donde los estudiantes habían realizado sus prácticas. Tras la pertinente transcripción y categorización de las entrevistas, los datos fueron analizados con el software MAXQDA 10.

Por otra parte, se aplicó un cuestionario a los estudiantes. La muestra de 60 alumnos de infantil y 117 de primaria representa el $50 \%$ de sus grupos totales de referencia-población; todos ellos corresponden a alumnos de último curso de la tercera promoción de egresados en el nuevo plan formativo.

El cuestionario previamente validado y ajustado a las dimensiones genéricas de las entrevistas, se formalizó en torno a dos grandes dimensiones - i) estructura y organización del Prácticum dentro del modelo de formación y la ii) formación profesional preconizada. La dimensión estructura y organización incluye los indicadores relacionados con la organización general de la formación del profesorado fruto de la inserción en el Espacio Europeo de Educación Superior $(E E E S)^{2}$ y los cambios más relevantes de la implementación del Plan de Bolonia, desde la consideración del perfil profesional hasta la formación práctica en escenarios profesionales.

La dimensión formación profesional comprende las vertientes de la formación de maestros en los contextos de Prácticum en busca de profesionales más capaces, autónomos, críticos, o sea, competentes. Esta dimensión comprende: el "aprendizaje profesional"; el "conocimiento profesional"; la "socialización profesional" y la "identidad profesional".

Los guiones de la entrevista y el cuestionario fueron validados mediante el análisis de validez de contenido con la técnica de jueces; además, se realizó el estudio de la confiabilidad del cuestionario mediante la prueba reliability, que arrojó un alpha de Cronbach

2 Aunque ya se ha aludido a él al referirse al Proceso de Bolonia, podemos sintetizar que el EEES es el referente para la articulación de la formación de nivel superior de validez para el conjunto de la Unión Europea - marco de formación-, con especificidad común de arquitectura de títulos, estructura, titulaciones, perfiles profesionales, certificación, homologación, movilidad, etc. al estar insertos en un mercado único de trabajo. de 0,967 para el conjunto de las dimensiones del instrumento. Los datos fueron analizados con el paquete estadístico SPSSX-21.

\section{Resultados}

Resultados de las entrevistas de los tutores

Los resultados relativos a la valoración de los tutores de Prácticum de la universidad, que se evidencian en las entrevistas y consideran las dos dimensiones de Estructura y Organización y Formación Profesional (gráfico 2), demuestran una superioridad en la frecuencia en aspectos organizativos $(f=699)$ frente a los aspectos curriculares de formación $(f=431)$, indicador de una mayor preocupación de la universidad por la primera dimensión.

En la organización estructural, los datos subrayan las funciones y tareas de los tutores universitarios $(f=46)$, no raras veces coligadas a los ratios tutorestudiantes $(f=24)$, la complejidad de asignación de tutores ( $f=38$ ) y los procesos colaborativos y de colegialidad entre tutores de Prácticum $(f=18)$. Es decir, esta categoría abarca aspectos directamente relacionados con el Prácticum en la universidad ( $f=176$ ), pero también en los centros $(f=162)$ y en los procesos de comunicación interinstitucional $(f=34)$. Uno de los coordinadores de Prácticum sistematiza a respecto:

El problema que tenemos son las condiciones laborales y en tiempos de crisis más. Para crear estructuras para poder realizar prácticum de calidad hacen falta las condiciones. Y los tiempos no acompañan... La reducción es cada vez un ratio mayor de profesor-alumno. Lo que contabiliza la docencia cada alumno de Prácticum ha ido a menos y claro, esto hace que sea difícil... A los profesores exigiría llevar a cabo todo lo que son informes de evaluación, debatir, consensuar instrumentos, etc. Deberíamos tener la posibilidad y tener espacio y horas para visitar las escuelas, para fidelizar escuelas, de tener contacto. El problema es que tenemos escuelas y un profesor que puede preguntar: "¿si voy a la escuela, quién me paga el viaje?". La mayoría va a los centros y la mayoría tiene relación y visita las escuelas. Pero es más por voluntad que por lo que se le puede exigir por las horas y el peso que tiene el Prácticum (EP1C, 57-57)

Si se considera el contexto universidad, la diferencia entre el tiempo establecido y el tiempo real destinado a las tutorías/seminarios en la facultad $(f=91)$

3 Magis no corrige las entrevistas de las investigaciones que publica y presenta los registros orales tal como los produjo cada encuestado. 
constituye un problema, ya que no permite un trabajo con "la profundidad necesaria y deseable". Y se acrecienta:

El Prácticum requiere individualizar bastante la situación, la reflexión tiende bastante a ser individual, porque el contexto, la relación con el maestro, la diversidad del aula, las características de aquella aula son características de aquel centro. ...Con un grupo de 10-12 alumnos que les tienes que acompañar en situación individuales [sic] y te exige verte con ellos a solas. Y si tú tienes un prácticum que las horas son las que sean, por 10 alumnos te podrían contar 90 horas y hacer 500 (EP1C, 92-92).

Otro aspecto subrayado es la atribución del Prácticum a tutores universitarios $(f=38$ ) con y sin formación y experiencia profesional, determinada por factores de organización del departamento y no tanto por la continuidad o experiencia profesional. Si bien la colaboración entre tutores está presente $(f=18)$, solo es señalada en el equipo de tutores de cada uno de los Prácticum.

Gráfico 2

Dimensiones y categorías de los tutores universitarios

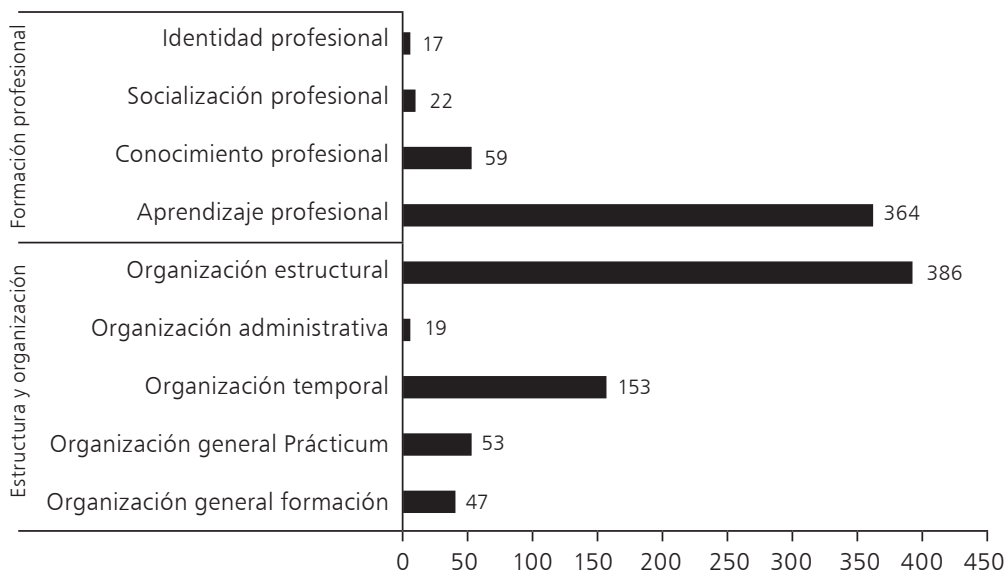

Fuente: elaboración propia

Al considerar la organización estructural, los entrevistados enfatizan la complejidad y dificultad del proceso de selección de los centros $(f=53)$ que "tienen que cumplir unos requisitos" (EP1C, 68-68), los procesos de cooperación entre los dos contextos de formación $(f=30)$ y la comunicación viabilizada por la visita de los tutores universitarios a los centros para el seguimiento de estudiantes ( $f=47$ ).

Dónde nosotros tenemos que mejorar en la Universidad es porque aprendemos de las escuelas, es decir, tú vas a las escuelas y tu discurso teórico en función de lo que tú estás relacionado con el día a día; nosotros ya no estamos en una escuela (EP1C, 94).

Este aspecto suele estar relacionado con factores de organización administrativa como la presencia/ausencia de recursos humanos $(f=12)$ y materiales/económicos ( $f=13$ ). Estos factores tienen consecuencias en los procesos colaborativos $(f=34)$ entre los dos contextos de formación que crean incoherencias, como se pone de manifiesto en: 
Aquí hay una cuestión muy complicada. Naturalmente, estas intervenciones deben ser congruentes con el modo de trabajo que se lleva en la escuela. Pero también debe ser congruente con la manera y los criterios para la enseñanza que se han trabajado desde la Facultad. Entonces, con una cierta frecuencia, más frecuencia que sería la deseada, entre las dos maneras existe incongruencias o contradicciones. Creo que esto, por una parte es un problema muy importante, pero por otra parte es una ocasión para que los estudiantes comprendan la complejidad del sistema educativo (EP3, 45-45).

Por lo que se refiere a la dimensión de Formación profesional (gráfico 3) los aprendizajes profesionales $(f=351)$ de los estudiantes en el contexto de Prácticum están más presentes.

Gráfico 3

Categorías de la dimensión formación profesional

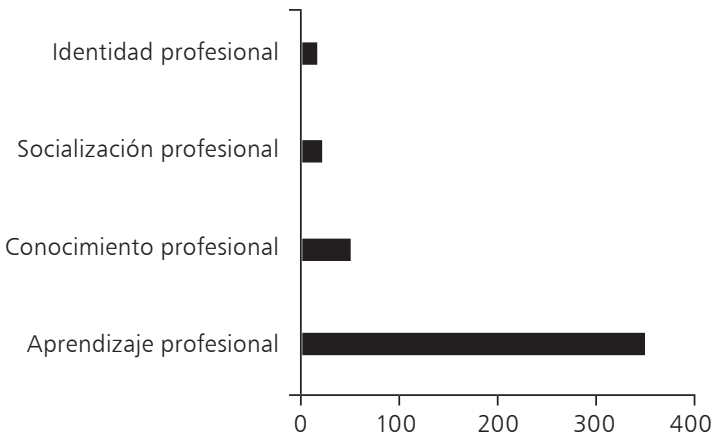

Fuente: elaboración propia
Gráfico 4

Indicadores de aprendizaje profesional

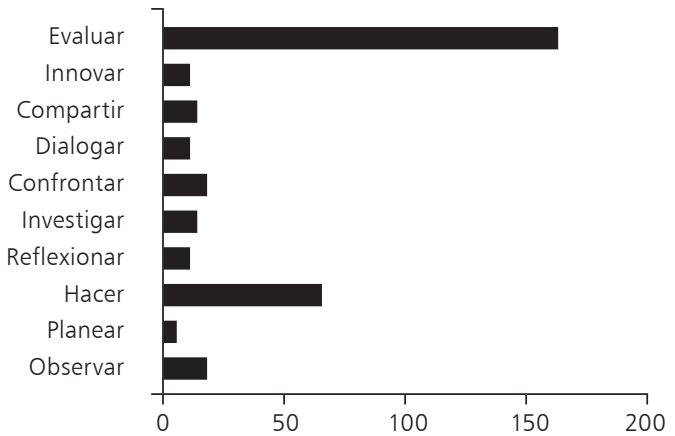

Fuente: elaboración propia

La evaluación ( $f=162)$ se destaca entre los resultados de Aprendizaje profesional (gráfico 4) pues subyace al nuevo plan de formación, aquí se pone de manifiesto en:

Pero ha cambiado, las estructuras de las asignaturas, antes la evaluación y los programas eran diferentes. ...Pero creo que la estructura y montaje del programa, el hecho de que ahora tenemos dividido, por ejemplo, las asignaturas en una dedicación de aprendizaje autónomo, una dedicación de aprendizaje supervisado, es decir, las tutorías, clases presenciales ya sean magistrales o seminarios, pero existen también estas clases (EP1C, 21-21).

Se verifica una preocupación con los sistemas de evaluación que, con una guía referencial para todos los supervisores de grado, permiten diferentes miradas de los tutores universitarios.

El "hacer" también asume valores considerables $(f=65)$ cuando lo comparamos con las restantes variables, o sea, las oportunidades que los estudiantes poseen de experimentar propuestas educativas en contextos reales y concretos de trabajo están fortalecidas. Este proceso de "hacer" está asociado al proceso de observación $(f=18)$ y a la necesidad de dialogar y negociar con los maestros tutores y con los tutores de universidad $(f=11)$. El uso de herramientas digitales, como el Campus Virtual o el Dropbox $(f=14)$, trae ventajas operacionales relevantes, ya que funciona 
como una estrategia para compartir y un complemento de las tutorías presenciales. Así,

Cada Prácticum tienen un campus virtual, (...) es fácil, lo compartimos, es para todos los alumnos y todos los profesores de todos los prácticum (...) si yo cuelgo un artículo para un alumno lo pueden ver todos, aunque no sea mi tutor (...) (El1C, 103-103). Además, los tutores sienten que "nosotros somos como el dropbox. ¿Sabes el dropbox? Pues abrimos una carpeta y los alumnos van colocando sus cosas allí y tú vas leyendo y viendo" (EI5, 4-4).

Pero esto permite que:

Yo diría que hay un vínculo muy estrecho, porque los correos electrónicos van y vienen. El contacto que tiene el tutor con las alumnas es mucho más próximo que en una clase ordinaria, y esto también es muy rico para las dos partes. Da mucho trabajo, son tutorías en pequeño grupo pero es casi individual al final, porque tienes que pensar muchas cosas muy diferentes para cada alumna y el contacto es muy directo y hay una relación de confianza más grande (EI2, 29-29).

El proceso de reflexión ( $f=13$ ) sobre las observaciones o intervenciones desarrolladas a lo largo del Prácticum son parte integrante de las tutorías en la universidad y de los registros diarios y finales pues permiten una confrontación entre teoría y práctica $(f=20)$. Todavía "el montaje de la carpeta de aprendizaje no está unificado en todos los departamentos" (EP1C, 82-82).

La categoría de socialización profesional $(f=18)$ (gráfico 3) suele estar debilitada, si bien parece implícita en el abordaje al diálogo entre maestro-estudiante, profesor-estudiante o bien en las tutorías conjuntas:

Y si no pasamos por una escuela, no nos enteramos de lo que los alumnos quieren aprender. $Y$ estamos situados en un aura, me refiero al profesorado universitario, que a veces no es la realidad que luego vivirán los alumnos que intentamos transmitirles y enseñarles (EP1C, 94-94).

El Prácticum es un tiempo y espacio de gran significación y relevancia para los futuros maestros que proporciona un conocimiento profesional de la realidad educativa ( $f=46$ ) en un determinado contexto real mediante la inmersión en su actividad laboral futura:

Y sí que puedes hacer tutorías, yo al principio cuando he hecho de tutor en las primeras las hago compartidas, porque quiero que comparen con los compañeros y que vean las dificultades, los diferentes centros, vean que otros no tienen la misma suerte, las exigencias (EP1C, 92-92).

La construcción de la identidad profesional $(f=$ 16) suele estar presente de forma exigua, pero sutilmente implícita y asociada a las reflexiones/autoevaluaciones que los estudiantes hacen a lo largo de las tutorías en la universidad y en los registros de evaluación. Se pretende que:

Descubran y que sobre todo al final hagan una reflexión crítica sobre cómo su adquisición de conocimiento y de sus propias competencias (...) se vea cómo en un futuro profesional se puede relacionar con este mundo educativo (EP1, 25-25).

Además,

Pienso que también está bien porque desde el primer año se sitúan, esto es lo mío o no lo es. Y también como realización profesional de verse en contexto, aunque normalmente no son muy críticas. Pero es un elemento más para ver si una alumna tiene más determinación respecto a lo que quiere ser (EI4, 157-157).

Por otra parte, los resultados relativos a la valoración de los tutores de Prácticum de los centros de prácticas, que se evidencian en las entrevistas, suelen focalizarse al contrario que en el caso anterior, en aspectos más formativos que organizacionales.

Considerando las dos dimensiones de Estructura y organización y Formación Profesional (gráfico 5), los datos demuestran una superioridad numérica en la frecuencia en aspectos de organización estructural del Prácticum $(f=90)$ frente a los aspectos de organización temporal $(f=28)$. Contrariamente a lo que ocurre con los tutores universitarios, el enfoque de los maestros tutores está localizado en la adquisición de competencias profesionales mediante las interacciones y comunicaciones entre los intervinientes (tutorías, tutores y comunicación interinstitucional), ya que las cuestiones organizativas del Prácticum (tiempos, duración, distribución por grados, etc.) son parte de la responsabilidad de la institución de formación y certificación, o sea, la universidad.

En la categoría organización temporal, en general, los maestros tutores creen que la distribución de los períodos de prácticas "están bien" y "son adecuados", pero subrayan la duración limitada de las intervenciones, además de las restricciones adyacentes a su periodicidad (el mismo día de la semana).

En la organización estructural, los datos señalan las complejas funciones y tareas de los tutores en los 
centros ( $f=29$ ), muchas veces relacionadas con la ausencia de comunicación entre los dos contextos de formación. Es decir, los maestros tutores relacionan algunos aspectos del Prácticum junto a sus "tutores universitarios" ( $f=9$ ), con el rol de los "maestros tutores" ( $f=29$ ) y los "tiempos de tutorías" en los centros $(f=12)$ y con procesos de "comunicación interinstitucional" $(f=40)$.

Gráfico 5

Dimensiones y categorías de los tutores de centro

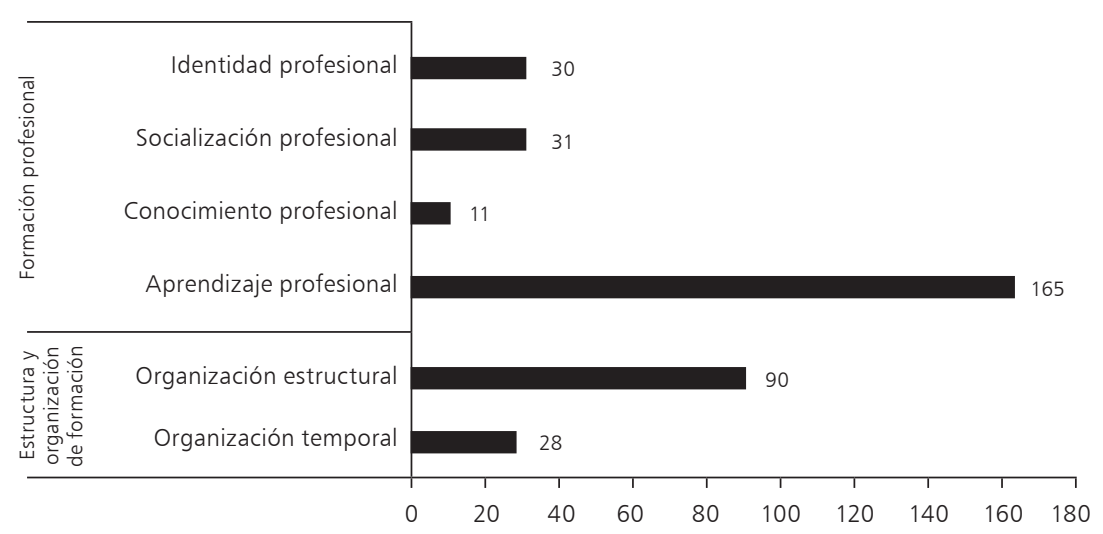

Fuente: elaboración propia

Al considerar el contexto Prácticum, el tiempo real para las tutorías ( $f=$ 28) constituye un problema, ya que la organización de los tiempos escolares de los centros, la diversidad de tareas del tutor y la constante indagación de los estudiantes hacen que la disponibilidad de tiempo de los maestros tutores en su acción pedagógica no se ajuste a la presencia de los estudiantes en el centro. Una tutora de centro verbaliza a este respecto:

No hay ese momento. Lo solemos hacer antes de empezar el día. O al medio día solemos comentar y plantear el funcionamiento de la clase. Depende mucho de la disponibilidad que podamos tener las dos, pero dentro del horario no hay ese momento. Quizás estaría bien, pero muchas veces es difícil encontrar ese momento. Siempre intentamos que los temas que quieren trabajar vayan en conjunto con la clase y eso lo hablamos sobre la marcha (ETP3, 26-26).

Tal como ocurre con los tiempos de tutorías en la universidad, aclarada en el tópico anterior, también se observa que la acción tutorial en los centros es débil, sin tiempos ni espacios formativos, de circularidad de saberes y de reflexión profunda.

Se enfatiza de forma generalizada e indudable en los procesos de ausencia de comunicación entre la universidad y los centros $(f=40)$, sugiriendo, a veces, alguna comparación con otras experiencias anteriores. A título de ejemplo, una maestra tutora dice:

Creo que sí [es problema], porque los tutores desde la universidad tienen muchas ideas y las trasladan a los alumnos que vienen aquí a hacer lo que les han pedido y muchas veces la realidad del aula es muy diferente. Vienen con ideas y quieren hacer cosas diferentes y muchas veces no podemos facilitar lo que ellos quieren por tiempo, por el currículo, por lo que sea. Si pudiéramos establecer un contacto directo con ellos pues facilitaría todo esto. Muchas veces se ven los alumnos un poco mareados, que les dicen una cosa en un sitio y otra en otro y parece que no vamos a una (ETP3, 8-8). 
Por lo que se refiere a la dimensión de Formación profesional (gráfico 6), lo más contemplado en las narrativas de los maestros tutores, tal como ocurre con los tutores universitarios, son los aprendizajes profesionales ( $f=$ 166) de los estudiantes en el contexto de Prácticum, lo que se contrapone a la frecuencia de elementos relativos a los conocimientos $(f=11)$ adquiridos en la universidad.

Gráfico 6

Categorías de la dimensión formación profesional

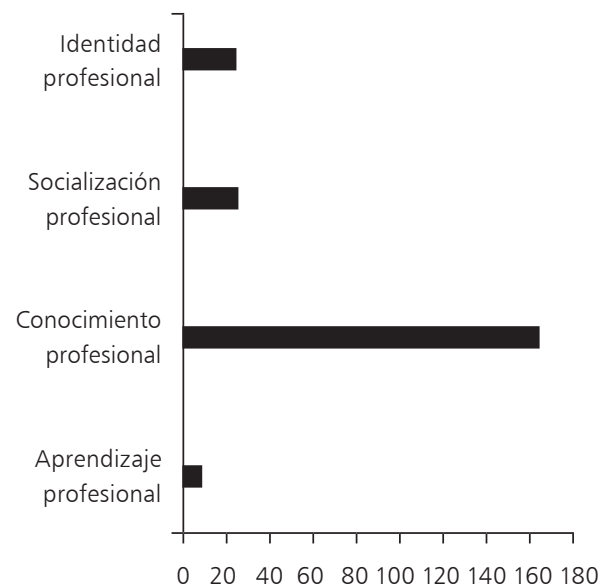

Fuente: elaboración propia
Gráfico 7

Indicadores de aprendizaje profesional

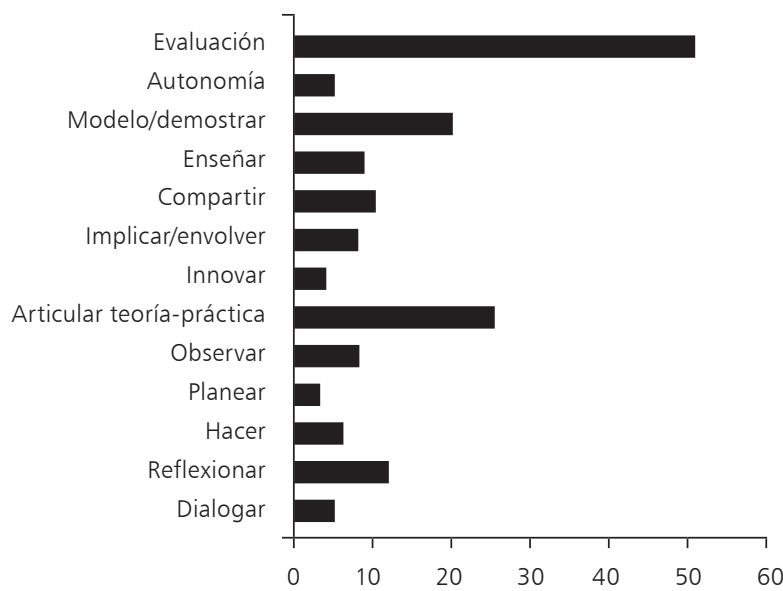

Fuente: elaboración propia

Al apuntar al aprendizaje profesional (gráfico 7), se verifica que la "evaluación" se destaca $(f=51)$ referida mediante observaciones, opiniones y preocupaciones realizadas al "formulario" o guía referencial de evaluación enviado por la universidad ( $f=12$ ), pero también alude a que cada uno "valora" en sus practicantes $(f=36)$. Relativo a la evaluación, una tutora refiere que "aquí sí que la relación entre el tutor de centro y el de la universidad sería importante, a la hora de ponernos de acuerdo con estos aspectos relacionales que solo nosotros vemos" (ETI3, 37-37).

El rol del maestro tutor como "modelo" asume también valores considerables $(f=20)$ cuando lo comparamos con las restantes variables. Este rol de "modelo" del maestro tutor también está asociado al proceso de "enseñar" $(f=9)$, qué hace y cómo lo hace y, consecuentemente, asociada al proceso de "observación" ( $f=8$ ) y con influencia en la construcción de la identidad profesional del estudiante. Este acompañamiento del "modelo" requiere, todavía, oportunidades de "dialogar" ( $f=5)$ y "compartir" ( $f=10)$ entre el estudiante y el tutor, muy asociada a la acción tutorial y a la reflexión. Pero:

Aquí, tenemos un gran problema, aparte de estar como tutor de este alumno, tenemos nuestro horario y distintas cosas qué hacer. Muchas veces sí que quedan un poco colgados al medio día, sin mucho qué hacer, pero nosotros tenemos en ese horario, reuniones de ciclo, reuniones con los padres... Estaría bien que en ese momento pudiéramos tener un momento de feedback con ellos, el facilitar programaciones y recursos, pero nosotros los tutores no tenemos tiempos y fallamos por la dinámica que tenemos en el centro. No tenemos momentos de reflexión con ellos, el año pasado estuvimos todo el 
año diciendo eso, pero es muy difícil por la dinámica del cole. Aprovechamos, en el patio, subiendo las escaleras, cualquier momentito, pero un momento específico no lo hay (ETP3, 26-26).

El proceso de "reflexión" $(f=12)$ sobre las observaciones o intervenciones desarrolladas a lo largo del Prácticum surgen asociadas a dos vertientes profesionales de los intervinientes: por un lado, la formación y valoración del propio maestro tutor que tiene que reflexionar sobre sus prácticas, o sea, de autoevaluarse; y por otro lado, la reflexión sobre los conocimientos y las actitudes de los estudiantes en formación. Así,

Ayudan en el desarrollo del aula. Yo cuando he sido tutora de prácticas, me ha ayudado a reflexionar sobre mis prácticas educativas. Porque está allí el alumno y le tienes que explicar por qué haces la cosas, y de esa forma se obliga a reflexionar. Ayudan si hace falta dar algo más de atención a algún grupo de alumnos. Siempre vienen con alguna idea nueva que nos ayuda a evolucionar a las propias tutoras (EC1, 20-20).

Este proceso de reflexión lleva a los tutores a referirse ampliamente a la "(des)articulación teoría y práctica" ( $f=25$ ) que se verifica en la formación de los estudiantes. Si bien la percepción de que lo que la universidad enseña y el estudiante aprende en ella "es otra cosa" de lo que pasa en la escuela, es mayoritaria en los discursos de los maestros tutores, no es unánime. Es decir, si para unos maestros en la "universidad lo que te enseñan son conocimientos muy teóricos y creo que en momentos están muy alejados de la realidad" (ETP3, 47-47) o "una cosa es lo que te enseñan en la universidad y otra cosa es el día a día" (EC2, 32-32), para otros es "el hecho de poder comparar la teoría que aprenden en la universidad con lo que se aplica en la clase" (ETP2, 22-22).

La dimensión de socialización $(f=31)$ e identidad profesionales $(f=30)$ suelen estar debilitadas, si bien parece implícita en la colegialidad manifestada entre maestro tutor y estudiante. En estos procesos:

Si están mucho tiempo, a partir de las valoraciones que me hacen, ellos (alumnos) acaban por sentirse parte integrante del colegio. Si vienen solo un día a la semana, pues ese sentimiento no se tiene (...) y eso hace también que la relación no sea tan fluida, no es lo mismo el vínculo que tienes con una persona durante un mes y medio o dos, que si la ves una vez a la semana (EC2, 21-23).

No obstante, la construcción de la identidad profesional $(f=16)$ también suele estar sutilmente implícita y asociada a las evaluaciones y valoraciones sobre los conocimientos y actitudes de los estudiantes a lo largo de su Prácticum, lo que abre tiempos y espacios para que "desarrollen su propia forma de hacer" (ETP4, 36-36), "construyendo su propia forma de afrontar las situaciones" (ETI1, 16-16), pues "ser tutor es ser un guía sin tener la necesidad de llevarlos por la mano" (EC2, 72-72). Al respecto:

Yo lo que intento enseñar, no sé si lo consigo, es el espíritu crítico. Como yo hago las cosas no es la mejor manera. Es la mía, una que he desarrollado que yo considero buena. Que observen, quizás no lo expresen, pero que digan esta es una buena forma de resolver una situación o yo lo hubiera hecho de esta otra manera. Si me lo dicen, genial. Yo sí que en parte soy un modelo pero no el modelo. Intento mostrarle el funcionamiento del colegio. Intento recordar las dificultades que he tenido para poder ayudarles para que el día de mañana cuando se enfrenten a una clase (...) Me gusta crear un clima de confianza para que se sientan confortables para que aporten ideas (ETP2, 30-30). 
Resultados de los cuestionarios de los estudiantes

Los resultados obtenidos, a partir de los cuestionarios de los estudiantes, ponen de manifiesto, en relación con la valoración global de las diferentes dimensiones implicadas en el Prácticum, tal como se observa en la tabla 1 y el gráfico 1, un perfil desigual entre ambos grados universitarios, de manera que los estudiantes del grado de educación infantil puntúan por encima de sus homólogos del grado de educación primaria en todas las dimensiones globales, excepto en la valoración de las tutorías, el Prácticum en los centros y su valor para la formación de los profesionales de la educación, donde ambos colectivos presentan similar valoración.

Tabla 1

Dimensiones globales/Estudios de grado

\begin{tabular}{l|c|c|c|c}
\hline & Infantil 1 & Primaria 2 & Significación & Diferencia \\
\hline Organización & 2,98 & 2,75 &, 01 & $1>2$ \\
\hline Tutoría & 3,98 & 3,70 & & \\
\hline Seminario & 3,71 & 3,42 &, 013 & $1>2$ \\
\hline Prácticum centros & 3,68 & 3,72 & & $1>2$ \\
\hline Tutor universitario & 3,56 & 3,35 &, 05 & $1<2$ \\
\hline Tutor centro & 3,50 & 3,76 &, 036 & \\
\hline Formación & 4,26 & 4,18 & & \\
\hline \hline
\end{tabular}

Fuente: elaboración propia

Gráfico 8

Dimensiones globales/Estudios de grado

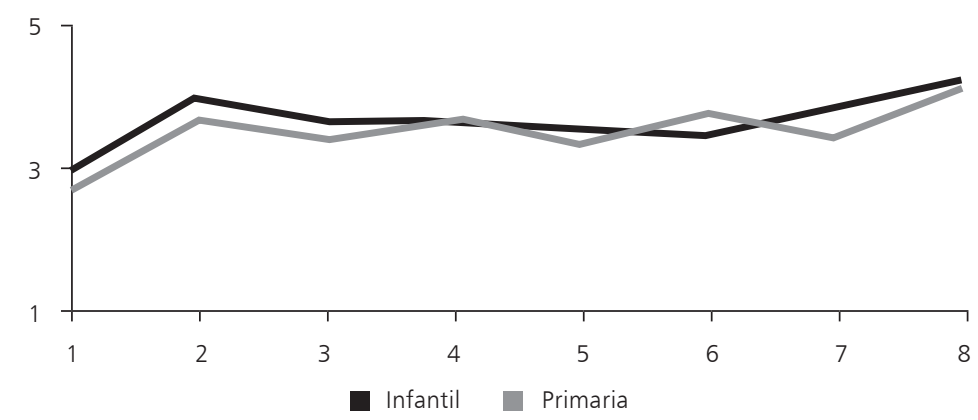

Fuente: elaboración propia

En relación con la percepción sobre la organización del Prácticum, los estudiantes valoran, como puede observarse en la tabla 2, que la distribución y permanencia de los tiempos de Prácticum, la inversión de tiempo de trabajo autónomo, el proceso de asignación de centros, la escasa información sobre el centro de prácticas y su contexto y la colaboración de las distintas asignaturas para el trabajo de Prácticum son los aspectos más débiles de la propuesta organizativa y deberían mejorarse.

Justamente, este ámbito referido a la organización del Prácticum es el percibido como menos positivo. Por otra parte, en este mismo punto de la organización, los estudiantes valoran más positivamente la información facilitada sobre cómo organizar el Prácticum y la distribución de las tutorías. 
Tabla 2

Percepciones sobre la organización del Prácticum /Estudios de grado

\begin{tabular}{|c|c|c|c|c|c|}
\hline & & Infantil & Primaria & Significación & Difrencia \\
\hline 1 & $\begin{array}{l}\text { La información facilitada sobre la organización general y objetivos del } \\
\text { Prácticum fue presentada al inicio de cada curso. }\end{array}$ & 3,54 & 3,14 & 011 & $1>2$ \\
\hline 2 & La distribución de los tiempos de Prácticum en cada curso es suficiente. & 2,98 & 2,18 &, 000 & $1>2$ \\
\hline 3 & $\begin{array}{l}\text { Los créditos de la asignatura corresponden a las horas de estudio } \\
\text { y de trabajo autónomo necesarias. }\end{array}$ & 3,22 & 2,69 & 001 & $1>2$ \\
\hline 4 & $\begin{array}{l}\text { La dinámica de trabajo a seguir en la asignatura se ajusta al tiempo } \\
\text { disponible. }\end{array}$ & 3,13 & 2,86 &, 05 & $1>2$ \\
\hline 5 & $\begin{array}{l}\text { Los estudiantes tienen conocimiento previo de los centros } \\
\text { y grupos etarios para poder decidir su opción. }\end{array}$ & 1,74 & 1,72 & & \\
\hline 6 & El proceso de asignación de centros de Prácticum es correcto. & 2,10 & 2,41 & & \\
\hline 7 & La información sobre los proyectos educativos de los centros es apropiada. & 2,24 & 2,54 & & \\
\hline 8 & El centro tiene conocimiento del perfil/trabajo de intervención del alumno. & 2,47 & 2,19 & & \\
\hline 9 & $\begin{array}{l}\text { El centro organiza las condiciones apropiadas a la construcción y } \\
\text { desarrollo de proyectos innovadores de los estudiantes. }\end{array}$ & 3,12 & 3,14 & & \\
\hline 10 & $\begin{array}{l}\text { El centro promueve oportunidades de intervención de los estudiantes } \\
\text { con proyectos que abarquen las familias, otros agentes educativos } \\
\text { y la comunidad. }\end{array}$ & 2,72 & 2,65 & & \\
\hline 11 & El centro está abierto a cambios propuestos por los estudiantes. & 2,83 & 2,97 & & \\
\hline 12 & $\begin{array}{l}\text { Los centros disponibles para el Prácticum ofrecen garantías de calidad en } \\
\text { la formación de maestros. }\end{array}$ & 2,83 & 2,93 & & \\
\hline 13 & $\begin{array}{l}\text { La distribución de horas de tutorías de Prácticum del profesor tutor de la } \\
\text { universidad es suficiente. }\end{array}$ & 3,65 & 3,62 & & \\
\hline 14 & La distribución temporal del Prácticum a lo largo del curso es adecuada. & 2,88 & 2,20 &, 000 & $1>2$ \\
\hline 15 & El tiempo de permanencia en los centros es suficiente. & 2,89 & 2,41 &, 001 & $1>2$ \\
\hline 16 & $\begin{array}{l}\text { El grado de exigencia en cada Prácticum corresponde a los aprendizajes } \\
\text { adquiridos en la universidad. }\end{array}$ & 3,57 & 3,24 &, 035 & $1>2$ \\
\hline 17 & $\begin{array}{l}\text { La relación entre el grado de dificultad de las intervenciones y los } \\
\text { conocimientos adquiridos en cada curso es adecuada. }\end{array}$ & 3,67 & 3,44 & & \\
\hline 18 & $\begin{array}{l}\text { En Prácticum, la articulación entre teoría y práctica, entre los aprendizajes } \\
\text { en la universidad y la realidad es evidente. }\end{array}$ & 3,47 & 2,84 &, 000 & $1>2$ \\
\hline 19 & $\begin{array}{l}\text { La articulación entre los contenidos aprendidos en las diferentes } \\
\text { asignaturas y las exigencias del Prácticum es satisfactoria. }\end{array}$ & 3,42 & 3,08 & 013 & $1>2$ \\
\hline 20 & $\begin{array}{l}\text { Los profesores de otras asignaturas ayudan cuando solicitados sobre su } \\
\text { área científica (planificación, materiales, actividades innovadoras, etc.). }\end{array}$ & 3,00 & 2,95 & & \\
\hline
\end{tabular}

Fuente: elaboración propia

Gráfico 9

Percepciones sobre la organización del Prácticum /Estudios de grado

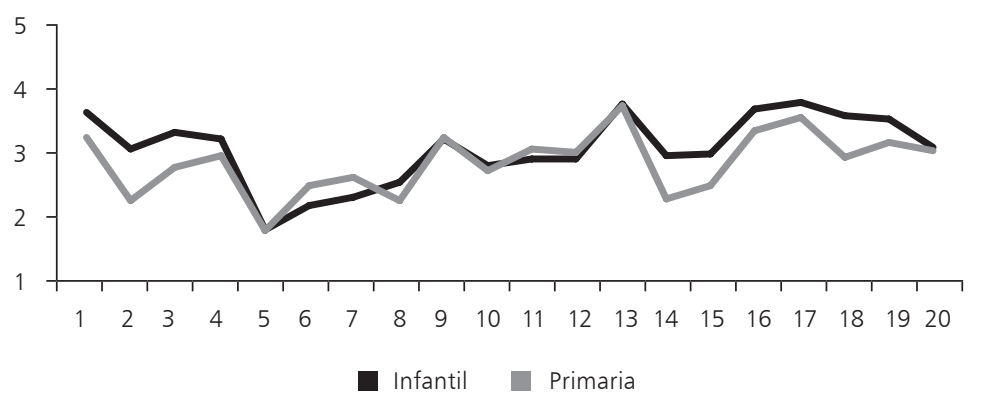

Fuente: elaboración propia 
Otro de los ejes importantes en el desarrollo del Prácticum es la tutoría por parte de tutores universitarios y maestros tutores de prácticas. En ambos casos, todas las valoraciones de los estudiantes se sitúan por encima de la media teórica por lo que podemos afirmar que la percepción es suficiente.

Tabla 3

Tutorías universitarias/Estudios de grado

\begin{tabular}{|c|c|c|c|c|c|}
\hline & & Infantil & Primaria & Significación & Diferencia \\
\hline 1 & $\begin{array}{l}\text {... son útiles para analizar el proceso de desarrollo } \\
\text { del Prácticum. }\end{array}$ & 4,19 & 3,96 & & \\
\hline 2 & ... se desarrollan en fechas adecuadas. & 4,03 & 3,60 &, 042 & $1>2$ \\
\hline 3 & $\begin{array}{l}\text {... son tiempos de intercambio de ideas/dificultades } \\
\text { de los distintos planes de trabajo para favorecer la } \\
\text { reflexión compartida. }\end{array}$ & 3,97 & 3,76 & & \\
\hline 4 & $\begin{array}{l}\text {... tienen un número de estudiantes por grupo/tutor } \\
\text { adecuado. }\end{array}$ & 4,12 & 3,96 & & \\
\hline 5 & $\begin{array}{l}\text {... el intercambio y la reflexión compartida promueven la } \\
\text { investigación para la acción. }\end{array}$ & 3,83 & 3,31 & 011 & $1>2$ \\
\hline 6 & $\begin{array}{l}\text {... son eficaces por la contribución de tutores para aclarar } \\
\text { aspectos científicos y pedagógicos de situaciones ocurridas. }\end{array}$ & 4,05 & 3,85 & & \\
\hline 7 & $\begin{array}{l}\text {... permiten un análisis y discusión de los aprendizajes } \\
\text { que aporta información pertinente y funcional para un } \\
\text { mejor desempeño. }\end{array}$ & 3,95 & 3,81 & & \\
\hline 8 & $\begin{array}{l}\text {... proveen el intercambio de proyectos individuales } \\
\text { que incrementan el conocimiento de distintas } \\
\text { realidades/contextos. }\end{array}$ & 3,69 & 3,50 & & \\
\hline 9 & $\begin{array}{l}\text {... son tiempos de aprendizaje que permiten crear una } \\
\text { identidad profesional. }\end{array}$ & 3,49 & 3,52 & & \\
\hline 10 & ... permiten una relación personal con el profesor tutor. & 4,27 & 4,02 & & \\
\hline 11 & $\begin{array}{l}\text {... son espacios de confrontación y articulación entre la teoría } \\
\text { y la práctica. }\end{array}$ & 3,78 & 3,45 & & \\
\hline 12 & $\begin{array}{l}\text {... son espacios de formación marcados por las características } \\
\text { humanas del profesor tutor. }\end{array}$ & 4,14 & 3,86 & & \\
\hline 13 & $\begin{array}{l}\text {... suscitan objetividad, pensamiento crítico, responsabilidad, } \\
\text { valores y ética. }\end{array}$ & 3,89 & 3,53 & & \\
\hline
\end{tabular}

Fuente: elaboración propia

Gráfico 10

Perfil de tutorías universitarias/Estudios de grado

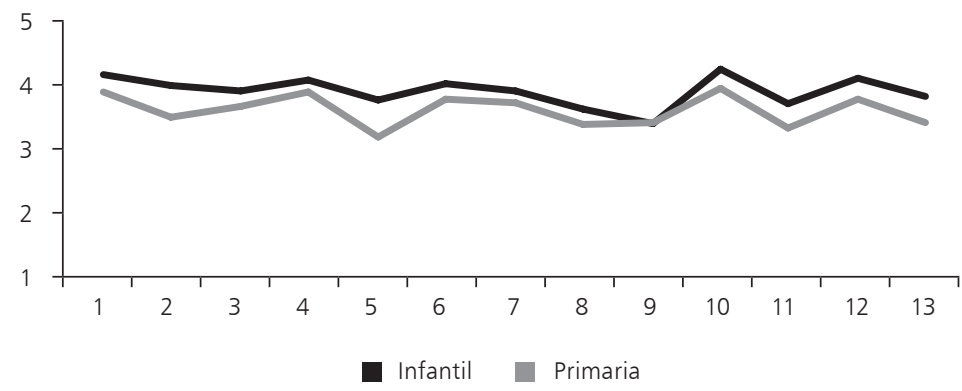

Fuente: elaboración propia 
Habría que comentar que, asumiendo esta valoración suficiente, hay aspectos mejor valorados que otros. Curiosamente, todo lo relativo a la tutoría dirigida a resolver problemas y dudas sobre el trabajo concreto en el centro de prácticas propuesto por la universidad es el aspecto mejor valorado, mientras que las tutorías dirigidas al análisis, reflexión en y desde la acción son los aspectos menos valorados en el conjunto. Esta idea nos lleva a pensar que los estudiantes están más cerca de un Prácticum más técnico que reflexivo, en el que lo importante es el diseño, desarrollo y evaluación de una acción formativa que deben desarrollar en el centro, más que la reflexión y mejora sobre el "qué" y el "cómo" hacerlo. En este sentido, algunas entrevistas con maestros tutores lo manifiestan e indican que hay pocos espacios y tiempos destinados a la reflexión durante y después de la clase realizada por el estudiante en práctica.

Similar valoración en los estudiantes de ambos grados, si bien en esta dimensión se presentan dos aspectos diferenciales a favor de educación infantil, relativos a tutorías que se desarrollan en las fechas adecuadas, el intercambio y la reflexión compartida promueven la investigación para la acción.

Las percepciones de los estudiantes sobre los tutores universitarios y de centros de prácticas y sus respectivos roles es positiva y todas las puntuaciones se sitúan por encima de la media teórica pero ninguna superior a 4 puntos sobre una escala de 5 .

Respecto los tutores universitarios, las cuestiones que son valoradas con puntuaciones más bajas son aquellas que tienen qué ver con el acompañamiento, la potenciación de la investigación y la reflexión y la visita a los centros.

Tabla 4

Tutores universitarios/Estudios de grado

\begin{tabular}{|c|c|c|c|c|c|}
\hline & & Infantil & Primaria & Significación & Diferencia \\
\hline 1 & $\begin{array}{l}\text {... ayuda a los estudiantes en horarios no establecidos } \\
\text { para tutorías por medio de atención personal o utilizando } \\
\text { recursos tecnológicos. }\end{array}$ & 3,65 & 3,49 & & \\
\hline 2 & $\begin{array}{l}\text {... conceptualiza, clarifica y formaliza los saberes científicos } \\
\text { al promover la construcción del conocimiento profesional } \\
\text { del estudiante. }\end{array}$ & 3,68 & 3,56 & & \\
\hline 3 & $\begin{array}{l}\text {... visita los centros para desarrollar la formación profesional } \\
\text { del estudiante. }\end{array}$ & 3,66 & 3,12 &, 005 & $1>2$ \\
\hline 4 & $\begin{array}{l}\text {... actúa como fuente de información sobre las características } \\
\text { de los centros. }\end{array}$ & 2,88 & 2,29 &, 000 & $1>2$ \\
\hline 5 & $\begin{array}{l}\text {... promueve la investigación y reflexión basada en las } \\
\text { experiencias personales vividas por los estudiantes. }\end{array}$ & 3,58 & 3,23 &, 028 & $1>2$ \\
\hline 6 & $\begin{array}{l}\text {... asesora el diseño del plan de trabajo con actividades/ } \\
\text { proyectos integradores de diferentes áreas del conocimiento. }\end{array}$ & 3,77 & 3,64 & & \\
\hline 7 & $\begin{array}{l}\text {... participa en la construcción de intervenciones para } \\
\text { promover la innovación. }\end{array}$ & 3,64 & 3,57 & & \\
\hline 8 & $\begin{array}{l}\text {... facilita recursos (materiales y bibliográficos) para ampliar } \\
\text { conocimientos y diversificar prácticas. }\end{array}$ & 3,63 & 3,40 & & \\
\hline 9 & $\begin{array}{l}\text {... ayuda a construir la identidad profesional mediante } \\
\text { oportunidades de autonomía, pensamiento crítico, capacidad } \\
\text { reflexiva, emancipación. }\end{array}$ & 3,50 & 3,54 & & \\
\hline 10 & $\begin{array}{l}\text {... acompaña y efectúa supervisión con eficacia, flexibilidad } \\
\text { e imparcialidad }\end{array}$ & 3,56 & 3,40 & & \\
\hline 11 & $\begin{array}{l}\text {... establece una relación personal próxima y empática con } \\
\text { los estudiantes. }\end{array}$ & 3,71 & 3,62 & & \\
\hline
\end{tabular}

Fuente: elaboración propia 
Gráfico 11

Perfil de tutores universitarios/Estudios de grado

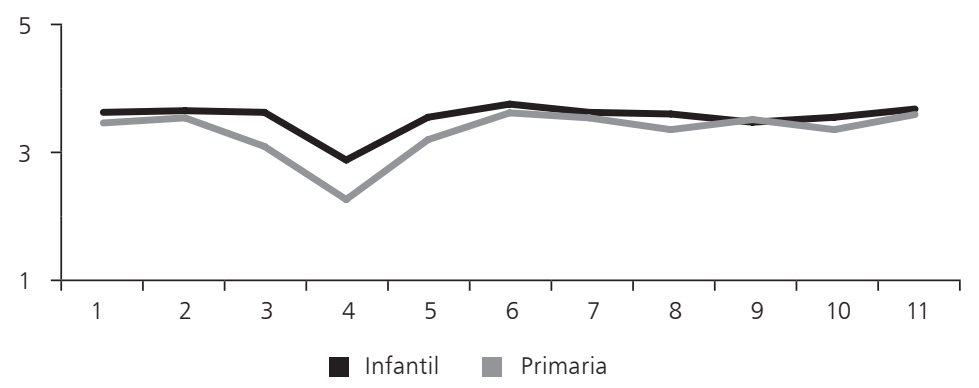

Fuente: elaboración propia

La valoración a los tutores universitarios por ambos grados de estudio es similar, excepto en lo relativo a visitas a los centros para desarrollar la formación, fuente de información y promoción de la investigación y la reflexión, que es superior en el grado de infantil.

En cuanto a los maestros tutores de prácticas, la valoración de los estudiantes sobre su función es más elevada que para los tutores universitarios, aunque tampoco superan puntuaciones de 4 . Si se destacan como aspectos mejor valorados el apoyo a la resolución de problemas, el asesoramiento en las actividades realizadas en el centro y la actitud como profesional de los tutores. En menor medida se valoran la información y documentación facilitada por el centro y la integración en los equipos del centro.

Tabla 5

Tutores de centro/Estudios de grado

\begin{tabular}{|c|c|c|c|c|c|}
\hline & & Infantil & Primaria & Significación & Diferencia \\
\hline 1 & $\begin{array}{l}\text {... prepara una acogida satisfactoria y explica el } \\
\text { funcionamiento del centro. }\end{array}$ & 3,71 & 3,85 & & \\
\hline 2 & $\begin{array}{l}\text {... presenta los estudiantes a todo el equipo profesional } \\
\text { del centro. }\end{array}$ & 3,37 & 3,37 & & \\
\hline 3 & $\begin{array}{l}\text {... facilita documentación para mejor análisis del centro } \\
\text { y su contexto. }\end{array}$ & 3,22 & 3,55 & & \\
\hline 4 & $\begin{array}{l}\text {... explica los programas/proyectos que se desarrollan } \\
\text { en el centro. }\end{array}$ & 3,40 & 3,78 & 027 & $1<2$ \\
\hline 5 & $\begin{array}{l}\text {... asesora el estudiante en sus actividades/proyectos } \\
\text { (antes/durante/después). }\end{array}$ & 3,65 & 3,89 & & \\
\hline 6 & ... apoya el estudiante en la resolución de problemas. & 3,82 & 3,99 & & \\
\hline 7 & $\begin{array}{l}\text {... facilita al estudiante materiales y recursos necesarios } \\
\text { al desarrollo de su proyecto de intervención. }\end{array}$ & 3,50 & 3,91 &, 008 & $1<2$ \\
\hline 8 & $\begin{array}{l}\text {... demuestra una actitud personal próxima con } \\
\text { el estudiante al colaborar en su construcción } \\
\text { de identidad profesional. }\end{array}$ & 3,83 & 4,03 & & \\
\hline 9 & $\begin{array}{l}\text {... realiza actividades como conceptualización, formalización } \\
\text { o demostración para promover el conocimiento profesional } \\
\text { de los estudiantes. }\end{array}$ & 3,48 & 3,64 & & \\
\hline 10 & $\begin{array}{l}\text {... conoce y respeta las orientaciones emanadas por } \\
\text { la universidad. }\end{array}$ & 3,20 & 3,66 &, 009 & $1<2$ \\
\hline 11 & $\begin{array}{l}\text {... tiene una acción pedagógica coherente con la formación } \\
\text { de los estudiantes en la universidad. }\end{array}$ & 3,33 & 3,75 & ,009 & $1<2$ \\
\hline
\end{tabular}

Fuente: elaboración propia 
Gráfico 12

Perfil de tutores de centro/Estudios de grado

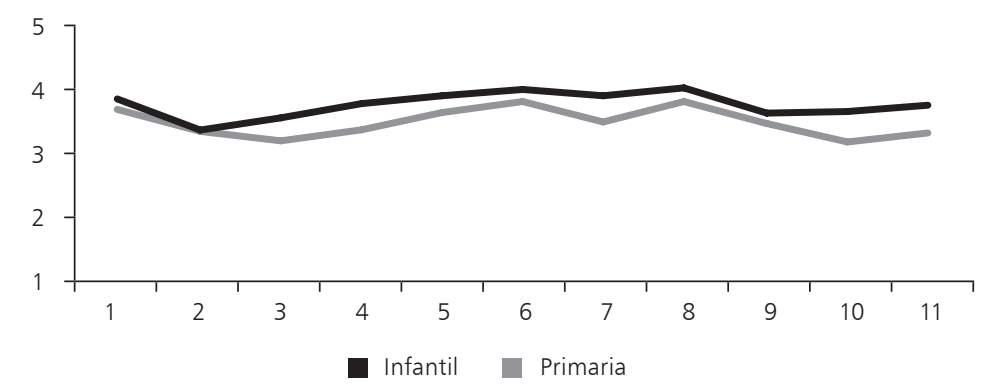

Fuente: elaboración propia

La valoración de los maestros tutores es desigual para los estudiantes de grados y se apunta un perfil valórico superior en los estudiantes del grado de primaria, específicamente en lo relativo a la explicación de los programas o proyectos de centro, facilitación de materiales y recursos para el desarrollo del proyecto, conocimiento y respeto a las orientaciones emanadas por la universidad y la coherencia de la acción pedagógica para la formación de los estudiantes.

La valoración del Prácticum como estrategia para la construcción de la identidad profesional, en términos generales, es muy positiva. Se destaca la idea que el Prácticum significa la oportunidad de vivenciar tareas profesionales, como espacio para experimentar y desarrollar competencias en relación con el diseño, desarrollo y evaluación de acciones de formación, como espacio para ampliar aprendizajes académicos y como aproximaciones a la realidad profesional. En este sentido, los estudiantes aprecian las virtualidades del Prácticum como escenarios de iniciación profesional y desarrollo de competencias profesionales.

Tabla 6

Percepciones sobre formación profesional y construcción identidad profesional

\begin{tabular}{|c|c|c|c|c|c|}
\hline & & Infantil & Primaria & Significación & Diferencia \\
\hline 1 & $\begin{array}{l}\text {... Un tiempo y un espacio en que el estudiante tiene } \\
\text { la oportunidad de experimentar y desarrollar } \\
\text { competencias profesionales. }\end{array}$ & 4,47 & 4,56 & & \\
\hline 2 & $\begin{array}{l}\text {... una experiencia formativa que concreta, complementa } \\
\text { y amplía los aprendizajes académicos. }\end{array}$ & 4,58 & 4,54 & & \\
\hline 3 & $\begin{array}{l}\text {... la primera aproximación/conocimiento de los } \\
\text { estudiantes a escenarios laborales reales. }\end{array}$ & 4,56 & 4,53 & & \\
\hline 4 & $\begin{array}{l}\text {... una experiencia formativa que posibilita la } \\
\text { construcción de la identidad profesional del estudiante. }\end{array}$ & 4,42 & 4,31 & & \\
\hline 5 & $\begin{array}{l}\text {... una oportunidad que los estudiantes tienen para } \\
\text { realizar procesos de investigación-acción-colaborativa. }\end{array}$ & 4,12 & 3,66 &, 008 & $1>2$ \\
\hline 6 & $\begin{array}{l}\text {... una posibilidad que el estudiante tiene para diseñar, } \\
\text { experimentar/desarrollar y evaluar su acción pedagógica } \\
\text { en un contexto real y concreto. }\end{array}$ & 4,47 & 4,47 & & \\
\hline 7 & ... una oportunidad de vivenciar tareas profesionales. & 4,65 & 4,59 & & \\
\hline
\end{tabular}




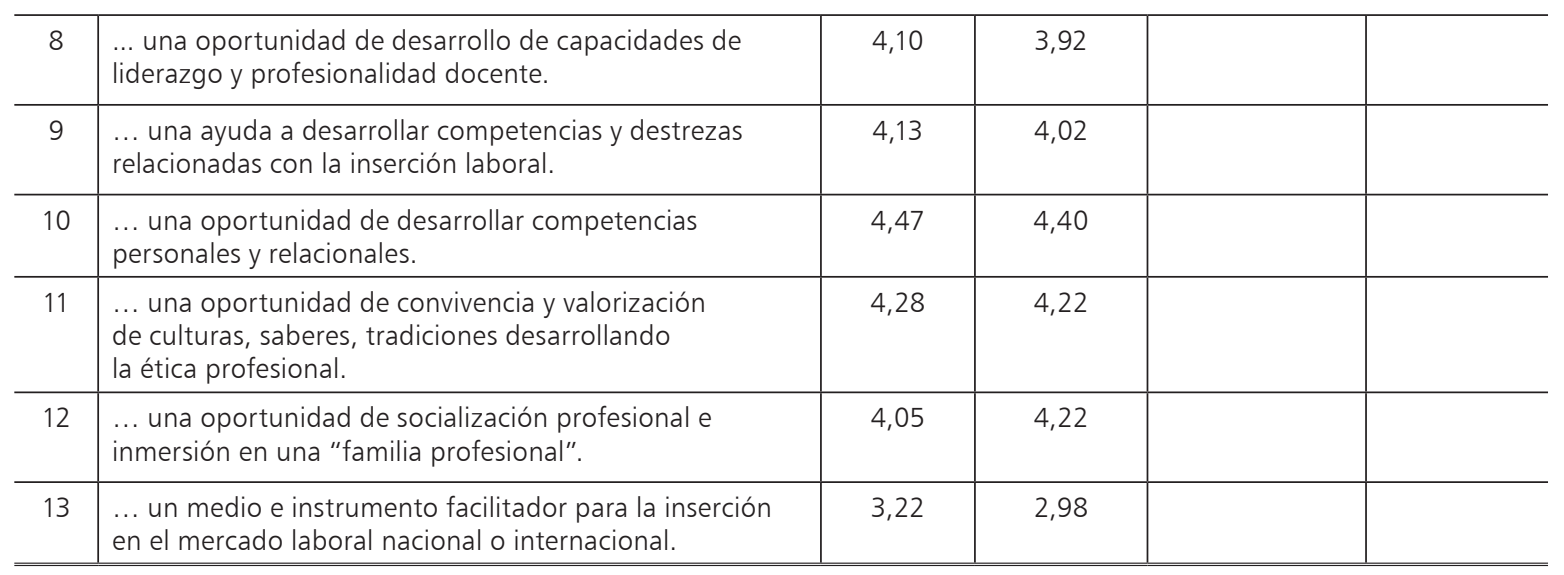

Fuente: elaboración propia

Gráfico 13

Perfil de formación/Estudios de grado

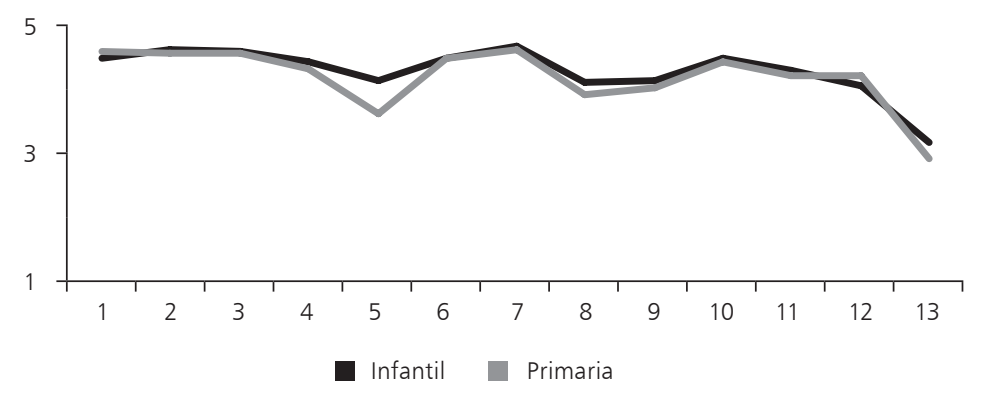

Fuente: elaboración propia

\section{Discusión de resultados y conclusiones}

Tras la presentación de los datos anteriores, es necesario sistematizar los diferentes aspectos analizados desde una lógica de la triangulación de las valoraciones de los actores, para mantener la organización en las grandes dimensiones.

Cuando consideramos la dimensión Estructura y organización del Prácticum, se destaca, globalmente, su fragilidad global, en comparación con las restantes dimensiones. Al triangular los datos cuantitativos de los estudiantes y los datos cualitativos de los tutores, se verifica que los estudiantes (valoraciones inferiores a 3) y los tutores universitarios consideran la duración y distribución del Prácticum a lo largo de los semestres y del grado como poco suficientes, "no permiten un trabajo con la profundidad deseable", mientras que la valoración es suficiente para los maestros tutores. El Prácticum es un tiempo y espacio de gran significación y relevancia para los futuros maestros, que les proporciona una inmersión en su actividad laboral futura en una "familia profesional", por lo que su temporalidad es determinante en la formación docente.

Los datos relativos a la organización estructural manifiestan también el frágil trabajo colaborativo entre los tutores universitarios y la ausencia de criterios de formación y experiencia profesional en la atribución de la asignatura. No obstante, se evidencia la necesidad de formación de los 
tutores universitarios en el dominio del desarrollo de competencias propias de las tutorías, coaching o mentoring (Veiga-Simão, Flores, Fernandes \& Figueira, 2008). Estos datos cualitativos son coincidentes con los datos cuantitativos, o sea, con la idea de los estudiantes (valoraciones inferiores a 3) cuando señalan la poca colaboración de otros profesores y de otras asignaturas para su trabajo en Prácticum.

En cuanto a lo organizacional, si bien partimos de la dimensión de más baja valoración de los datos cuantitativos de los alumnos (valoraciones por debajo de 3 en promedio), los tres grupos de informantes consideran, en algunos casos, una débil coordinación entre los tutores de universidad y los maestros tutores, y la casi ausencia de comunicación interinstitucional, lo cual confirma la percepción de ausencia, ineficacia o débil colaboración y coordinación entre la universidad y los centros, el distanciamiento de contextos de investigación-acción como parte integrante del proyecto formativo, así como el compromiso, la "coherencia", "centralidad", "complementariedad" (Zabalza-Beraza, 2013) y reciprocidad necesarias para un modelo de formación integrado.

Otro dato relevante que fragiliza la comunicación interinstitucional, revelado por todos los datos cualitativos y cuantitativos del estudio, está vinculado a la observación y orientación in situ del ejercicio profesional de cada estudiante y de sus competencias profesionales, tantas veces determinadas y afectadas por situaciones económicas, administrativas o de gestión. Estos tiempos pueden constituir un paso más en la formación de los futuros maestros, en la medida en que se están creando lazos y hábitos de colegialidad, hábitos de aprendizaje cooperativo y colaborativo para que se pueda pensar en las escuelas como comunidades de práctica (Korthagen, 2010; PalomaresMontero \& Chisvert-Tarazona, 2016; Romeu, Guitert \& Sangrà, 2015).

Si consideramos la dimensión Formación profesional, los datos, tanto cuantitativos como cualitativos, ponen el énfasis en los aprendizajes profesionales. Los tutores universitarios se focalizan principalmente en competencias procedimentales, del "hacer", de lo "deben de...", mientras los maestros tutores se focalizan en la observación y aprendizaje de modelos de "hacer" que sustentan, en ambos casos, la formación técnica o praxiológica. Juana Sancho-Gil y sus colaboradores (2014, p. 21) alertan sobre la necesidad de revisar "lo que en la formación se dice que debería ser o debería hacerse y el sentido o la falta de sentido que esto tiene para la práctica".

Los datos muestran que la acción tutorial, en lo organizacional, parece estar algo comprometida en la universidad y en los centros, por factores nebulosos. Por un lado, en la universidad, a partir de las entrevistas de los tutores, se observa que las ratios tutor-estudiante no facilitan la acción tutorial individualizada, ni en la universidad ni en los centros, por su dispersión. Para proporcionar esta comunicación entre estudiantes y tutores universitarios, surge, en voz de los tutores, el uso de herramientas tecnológicas como complemento de la acción tutorial —además de favorecer el compartir-, la comunicación asíncrona y la gestión de tiempo.

Por otro lado, la acción tutorial en los centros no está organizada en tiempos determinados y ocurre durante el tiempo de intervención del estudiante. Esta sobreposición y compleja tarea del maestro tutor en su acción pedagógica, acoplada a la tutorización de estudiantes de Prácticum, suele transformar la acción tutorial en tiempos de cambio de información y no tanto en tiempos de "reflexión sobre la práctica" (LopesMenino \& Blázquez-Entonado, 2012), "reflexión en la acción" (Tejada, 2012), reflexión "sobre" y "acerca de la acción" (Day, 2005), lo cual desaprovecha oportunidades para (re)construir los conocimientos profesionales por medio de los saberes "del" y "en el" trabajo (Tardif, 2004).

Los estudiantes perciben entonces este proceso de reflexión sustentado por dispositivos praxiológicos del maestro tutor y el apoyo a la resolución de problemas, el asesoramiento en las actividades y proyectos, y la actitud profesional de los maestros tutores (Nocetti de la Barra, 2016). Estas son también preocupaciones de los maestros tutores en su acción de tutorización. Estos aspectos, subrayados en los datos cualitativos y cuantitativos, nos pueden hacer pensar que el Prácticum está más diseñado en un perfil de profesor ejecutor/técnico que con un perfil de profesional reflexivo, que sea "capaz de indagar en su práctica" y "llevar a cabo acciones profesionales verdaderamente transformadoras".

Tanto las entrevistas a tutores como los cuestionarios a alumnos indican que las tutorías conjuntas son apuntadas como espacio y tiempo formativos, que incrementan la reflexión compartida y la socialización profesional, pero pueden reducir el desarrollo de competencias reflexivas e investigativas individuales y la circularidad de saberes, lo cual elimina oportunidades de desarrollo profesional para los estudiantes y para los maestros tutores (Veiga-Simão, Flores, Fernandes \& Figueira, 2008). Estas capacidades reflexivas y de pensamiento crítico superior (Carvalho, 2015; Carvalho \& Tejada, 2013) incluyen elementos del dominio cognitivo y del dominio afectivo (Day, 2005).

Cuando analizamos la identidad profesional, es posible observar el valor atribuido al Prácticum por todos los datos cualitativos y cuantitativos de los informantes y la importancia de las primeras experiencias laborales, ya que tienen un papel relevante en la forma 
como los futuros maestros se enfrentan a los cambios a lo largo de su trayectoria académica y laboral y cómo influye en su forma de ser profesor (Sancho-Gil, Hernández-Hernández, Martínez-Pérez, Padilla-Petry, Montané-López, Herraiz-García, Larraín-Pfingsthorn, Creus, Domingo-Peñafiel, Vidiella-Pagès, Correa-Gorospe, Aberasturi-Apraiz, Gutiérrez-Cuenca, Martínez-Arbelaiz, Fernández-Olaskoaga, Losada-Iglesias, 2014, p. 12). Los maestros tutores son esta primera imagen del mundo profesional que el estudiante reconoce (Martínez-Figueira \& Raposo-Rivas, 2011, p. 155) y cuando hablan de "modelo" profesional están integrando al estudiante en la iniciación a su actividad laboral futura, a emergerlo en su cultura profesional y en esta nueva familia profesional (Tejada-Fernández, 2009).

Por último, la valoración del Prácticum como estrategia para la construcción de la identidad profesional apuntada por los estudiantes (valoraciones superiores a 4), destaca sus virtualidades como escenarios de iniciación profesional y desarrollo de competencias profesionales, como un proceso hecho a tres. Por eso, la distancia entre los contextos de formación y sus consecuencias en la construcción de la identidad profesional del futuro maestro puede configurar un "aislamiento", ya que "los formadores de profesores en su globalidad están preocupados con el profesionalismo individual del futuro profesor y con el impacto múltiple que su acción podrá tener en los niños y en los jóvenes, pero no con el proceso de profesionalización y autonomía de los profesores, de lo cual no se sienten efectivamente participantes" (Pereira \& Lopes, 2014, p. 63).

Con todo, tras la triangulación y discusión de los resultados anteriores, hemos de concretar las siguientes conclusiones:

- Frágil trabajo colaborativo entre los tutores universitarios focalizado solo en el equipo de tutores de cada uno de los Prácticum y la ausencia de criterios de formación y experiencia profesional en la atribución de la asignatura puede, por un lado, fragilizar la gradual complejidad de la asignatura a lo largo del grado y, por otro, no garantizar la continuidad ni el nivel de confianza, de seguridad, de motivación cruciales para el desarrollo de competencias en los estudiantes.

- Débil coordinación entre los tutores de universidad y los maestros tutores, que puede dificultar la creación de espacios para la discusión y diseño de proyectos comunes e interconectados entre ambas realidades (académicas-formativas-profesionales), así como el consenso en los criterios y competencias a evaluar por ambas instituciones.

- Exigua observación y orientación in situ del ejercicio profesional de cada estudiante, de sus competencias profesionales, que son determinadas y afectadas por situaciones económicas, administrativas o de gestión, lo cual fragiliza la comunicación interinstitucional.

- Énfasis en los aprendizajes profesionales, principalmente en competencias procedimentales, del "hacer", de lo "deben de..." que sustenta el énfasis en la formación praxiológica.

- Las ratios tutor-estudiante no facilitan la acción tutorial individualizada ni en la universidad ni en los centros, pero enriquece la reflexión compartida y la socialización profesional. No obstante, el uso de herramientas tecnológicas como soporte y complemento de la acción tutorial favorece el compartir, la comunicación asíncrona y la gestión de tiempo. 
- Valoración de la reflexión individual y compartida, mediada por el rol del tutor universitario favorece los procesos de articulación teoría y práctica y las relaciones intrapersonales (saber-ser por medio del 'diálogo con el tú meditativo') e interpersonales (saberestar por medio de colegialidad, confianza, escucha activa, comunicación eficaz con sus pares).

Por último, cabe considerar las limitaciones encontradas en el desarrollo de nuestro estudio. De una parte, la situación de crisis económica, aunque no lo justifica en su totalidad, sí explicaría las problemáticas relativas a la coordinación, interconexión entre profesionales, ratios de alumnos, etc. desde la lógica de la intervención. De otra parte, desde una lógica más de la investigación, al estar ante un estudio de caso, y además limitado temporalmente en el último curso de formación universitaria de grado, solo se han podido afrontar las percepciones de los actores de la formación práctica. Sin lugar a dudas, un estudio de impacto de esta formación y de la construcción de la identidad, también en clave de seguimiento de egresados, puede arrojar nueva luz sobre nuestros propósitos investigativos. En esta dirección, dejamos lanzadas las nuevas líneas de investigación.

\section{Sobre los autores}

José Tejada-Fernández es licenciado en psicología y pedagogía. Catedrático de didáctica y organización escolar en el departamento de pedagogía aplicada, Universidad Autónoma de Barcelona. Especialista en evaluación, innovación y formación de formadores, ha ejercido su actividad docente e investigadora en estos campos, tanto en licenciatura, como en másteres y doctorados nacionales e internacionales.

Maria Lurdes Carvalho-Dias es docente del Instituto de Educación, Universidad do Minho (Portugal) y miembro del Centro de Investigación en Estudios del Niño. Su investigación se centra en la formación y desarrollo de profesores de educación básica y en las prácticas profesionales.

Carmen Ruiz-Bueno es doctora en ciencias de la educación. Actualmente, es profesora titular del departamento de pedagogía aplicada en el que desarrolla actividades de docencia en el campo de la didáctica. Participa activamente como miembro principal del Equipo de Investigación CIFO de la UAB en actividades de investigación relacionadas con la temática de formación y trabajo.

\section{Referencias}

Aguilera, Antonio; Mendoza, Marlen; Racionero, Sandra \& Soler, Marta (2010). El papel de la universidad en comunidades de aprendizaje. Revista Interuniversitaria de Formación del Profesorado, $67(24,1)$, 45-56. Disponible en: http://www.aufop.com/aufop/uploaded_files/ articulos/1268700514.pdf

Ballesteros-Moscosio, Miguel-Ángel \& Ries, Francis (2014). Internacionalización y construcción de la identidad profesional del profesor: investigación y praxis en un cruce de caminos. Revista Fuentes, 14, 11-18. DOI:10.12795/revistafuentes.2014.115.01. Disponible en: http://institu cional.us.es/revistas/fuente/15/INTERNACIONALIZACI\%C3\%93N\%20 Y\%20CONSTRUCCI\%C3\%93N.pdf

Carvalho, Maria Lurdes (2015). Iniciación a la práctica profesional: la mirada reflexiva de los estudiantes de educación básica. Revista de Estudios e Investigación en Psicología y Educación, Extra (6), 175-179. 
Disponible en: http://revistas.udc.es/index.php/reipe/article/down load/448/pdf_167

Carvalho, Maria Lurdes \& Tejada-Fernández, José (2013). Formación inicial de profesores: sinergias construyendo una nueva realidad. Documento mimeografiado. Bellatera: Departamento de Pedagogía Aplicada, Universidad Autónoma de Barcelona, UAB.

Coiduras-Rodríguez, Jordi Lluís (coord.) (2010). Las competencias del profesorado y los formadores de los centros colaboradores ante la alternancia de contextos en formación superior. VI Congreso Internacional de Docencia Universitaria e Innovación, CIDUI, Nuevos espacios de calidad en la Educación Superior. Barcelona, 30 de junio-1, 2 de julio.

Day, Christopher (2005). Formar docentes. Cómo, cuándo y en qué condiciones aprende el profesorado. Madrid: Narcea.

Korthagen, Fred A. J. (2010). La práctica, la teoría y la persona en la formación del profesorado. Revista Interuniversitaria de Formación del Profesorado, 68 (24,2), 83-101. Disponible en: http://www.aufop.com/ aufop/uploaded_files/articulos/1279236671.pdf

Lentzen, Sandra (2015). Los modelos de formación dual como integración de lo académico y lo laboral. En Manuela Raposo-Rivas, Pablo César Muñoz-Carril, María Ainoa Zabalza-Cerdeiriña, María Esther Martínez-Figueira, Adolfo Pérez Abellás (coords.). Documentar y evaluar la experiencia de los estudiantes en las prácticas, 5-8. Santiago de Compostela: Andavira Editora, S.A.

Lopes-Menino, Hugo Alexandre \& Blázquez-Entonado, Florentino (2012). La práctica pedagógica en la formación inicial de profesores del primer ciclo de enseñanza básica en Portugal. Enseñanza \& Teaching: Revista Interuniversitaria de Didáctica, 30 (1), 23-43. Disponible en: http://campus.usal.es/ revistas_trabajo/index.php/0212-5374/arti cle/viewFile/9295/9588

Lüdke, Menga (2009). Universidade, escola de educação básica e o problema do estágio na formação de professores. Revista Brasileira de Pesquisa: Formação Docente, 1 (1), 95-108. Disponible en: http://for macaodocente.autenticaeditora.com.br/artigo/exibir/1/5/1

Martínez-Figueira, María Esther \& Raposo-Rivas, Manuela (2011). Funciones generales de la tutoría en el Prácticum: entre la realidad y el deseo en el desempeño de la acción tutorial. Revista de Educación, 354, 155-181. Disponible en: http://www.revistaeducacion.mec.es/ re354/re354_07.pdf

Monereo, Carles \& Domínguez, Carola (2014). La identidad docente de los profesores universitarios competentes. Educación XX1, 17 (2), 83104. doi: 10.5944/educxx1.17.2.11480. Disponible en: http://www. redalyc.org/pdf/706/70630580005.pdf

Nocetti de la Barra, Alejandra (2016). Experiencia de reflexión de estudiantes de pedagogía en educación media en biología y ciencias naturales en las asignaturas de práctica pedagógica y profesional en una universidad de la región de Bío, Chile. Tesis doctoral, Departamento de Didáctica y Organización, Universidad de Barcelona. Disponible en: http://diposit.ub.edu/dspace/bitstream/2445/102037/1/ ANdIB_TESIS.pdf

Palomares-Montero, Davinia \& Chisvert-Tarazona, María José(2016). Cooperative Learning: A Methodological Innovation in Teacher Training. Cultura y Educación, 28 (2), 387-395. DOI: 10.1080/11356405.2016.1158448

Pereira, Fátima \& Lopes, Amélia (2014). Especificidades de la formación de profesores y profesión docente: reflexiones a partir de un estudio 
sobre los formadores de profesores y de enfermeros. En Juana M. Sancho, José Miguel Correa, Xavier Giró \& Leticia Fraga. Aprender a ser docente en mundo en cambio. Simposio Internacional, 57-66. Barcelona: Dipòsit Digital de la Universitat de Barcelona. Disponible en: http://som.esbrina.eu/aprender/docs/5/PereiraFatimaLopes Amelia.pdf

Rodríguez-Quezada, Estela; Cisterna-Cabrera, Francisco \& Gallegos-Muñoz, Cecilia (2011). El sistema de prácticas como elemento integrante de la formación profesional. Revista de la Educación Superior, $X L$ (159), 67-85. Disponible en: http://www.redalyc.org/articulo. oa?id=60422576004

Romeu, Teresa; Guitert, Montse \& Sangrà, Albert (2015). Teacher Collaboration Network in Higher Education: Reflective Visions from Praxis. Innovations in Education and Teaching International, 53 (6), 592-604. DOI: 10.1080/14703297.2015.1025807

Ruiz-Bueno, Carmen; Carvalho, Lurdes \& Tejada, José (2014). El prácticum en los procesos de adquisición de competencias profesionales y construcción de la identidad profesional en la formación de maestros de educación infantil y primaria: percepciones de los protagonistas. VII Congreso Internacional de Docencia Universitaria e Innovación ClDUI. Tarragona, 2-4 de julio.

Sancho-Gil, Juana M.; Hernández-Hernández, Fernando; Martínez-Pérez, Sandra; Padilla-Petry, Paulo; Montané-López, Alexandra; HerraizGarcía, Fernando; Larraín-Pfingsthorn, Verónica; Creus, Amalia Susana; Domingo-Peñafiel, Laura; Vidiella-Pagès, Judit; Correa-Gorospe, José Miguel; Aberasturi-Apraiz, Estibaliz; Gutiérrez-Cuenca, Luispe; Martínez-Arbelaiz, Asun; Fernández-Olaskoaga, Lorea \& LosadaIglesias, Daniel (2014). La construcción de la identidad docente del profesorado de educación infantil y primaria en la formación inicial y los primeros años de trabajo (Identidoc). En Juana M. Sancho, José Miguel Correa, Xavier Giró \& Leticia Fraga. Aprender a ser docente en mundo en cambio. Simposio Internacional, 11-23. Barcelona: Dipòsit Digital de la Universitat de Barcelona. Disponible en: http://diposit. ub.edu/dspace/bitstream/2445/50728/1/Esbrina-Aprender_docente _p11-23.pdf

Schön, Donald (1992). La formación de profesionales reflexivos. Hacia un nuevo diseño de la enseñanza y el aprendizaje en las profesiones. Madrid: Paidós.

Tardif, Maurice (2004). Los saberes del docente y su desarrollo profesional. Madrid: Narcea.

Tejada-Fernández, José (2006). El Prácticum. Actas de las Jornadas sobre el futuro Grado de Pedagogía. Barcelona: Edición Técnica Digital.

Tejada-Fernández, José (2009). Profesionalización docente en el escenario de la Europa de 2010. Una mirada desde la formación. Revista de Educación, 349, 463-477. Disponible en: http://www.revistaeduca cion.mec.es/re349/re349_22.pdf

Tejada-Fernández, José (2012). La alternancia de contextos para la adquisición de competencias profesionales en escenarios complementarios de educación superior: marco y estrategias. Educación XX1, 15 (2), 17-40. DOl:10.5944/educxx1.15.2.125. Disponible en: http://www. redalyc.org/pdf/706/70624504010.pdf

Tejada-Fernández, José (2013). Profesionalización docente en la universidad: implicaciones desde la formación. Revista de Universidad y Sociedad del Conocimiento, RUSC, 10 (1), 170-184. DOI: 
10.7238/rusc.v10i1.1471. Disponible en: http://www.redalyc.org/ pdf/780/78025711012.pdf

Tejada-Fernández, José \& Carvalho, Maria Lurdes (2013). El Prácticum en la formación inicial de maestros: percepciones de los tutores de universidad de educación infantil y primaria. En Pablo César Muñoz-Carril, Manuela Raposo-Rivas, Mercedes González-Sanmamed, María Esther Martínez-Figueira, María Ainoa Zabalza-Cerdeiriña \& Adolfo Pérez-Abellás. Actas XII Symposium Internacional sobre el Prácticum y las Prácticas en Empresas en la Formación Universitaria: Un Prácticum para la formación integral de los estudiantes, 1583-1596. Santiago de Compostela: Andavira. Disponible en: http://redaberta.usc. es/poio/documentos/actas/actas_poio_2013.pdf

Tejada-Fernández, José \& Ruiz-Bueno, Carmen (2013). Significación del Prácticum en la adquisición de competencias profesionales que permiten la transferencia de conocimientos a ámbitos propios de la acción docente. Profesorado. Revista de Curriculum y Formación del Profesorado, 17 (3), 92-110. Disponible en: http://www.redalyc.org/ articulo.oa?id $=56729527006$

Veiga-Simão, Ana Margarida; Flores, Maria Assunção; Fernandes, Sandra Raquel Gonçalves \& Figueira, Célia (2008). Tutoria no ensino superior: concepções e práticas. Revista Sísifo. Revista de Ciências da Educação, 07, 75-88.

Wenger, Étienne (2002). Comunidades de práctica: aprendizaje, significado e identidad. Madrid: Paidós.

Zabalza-Beraza, Miguel Ángel (2013). El Prácticum como contexto de aprendizajes. En Pablo César Muñoz-Carril, Manuela Raposo-Rivas, Mercedes González-Sanmamed, María Esther Martínez-Figueira, María Ainoa Zabalza-Cerdeiriña \& Adolfo Pérez-Abellás. Actas XII Symposium Internacional sobre el Prácticum y las Prácticas en Empresas en la Formación Universitaria: Un Prácticum para la formación integral de los estudiantes, 51-68. Santiago de Compostela: Andavira. Disponible en: http://redaberta.usc/poio, http://redaberta.usc.es/ poio/documentos/actas/actas_poio_2013.pdf 